20. R. Kollinz. Sredniy klass bez raboty: vyhody zakryvaiutsya. Est' li buduzhee u kapitalizma? [Middle class out of work: exits are closing. Is there a future for capitalism? Collection of articles by I. Wallerstein, R. Collins, M. Mann, G. Derlugyan, and K. Calhoun]. Gaidar Institute publishing house, Moscow (2015), pp. 61-112.

21. M. Mann. Konets, mozhet, i blizok, tol'ko dlya kogo? Est' libuduzheeukapitalizma? Sb. statey I. Vallerstaina, R. Kollinza, M. Manna, G. Derlug'yana, K. Kalhuna [The end may be near, but for whom? Is there a future for capitalism? Collection of articles by I. Wallerstein, R. Collins, M. Mann, G. Derlugyan, and K. Calhoun]. Gaidar Institute publishing house, Moscow (2015), pp. 113-155.

22. J. Gorenfeld. The producer from hell. Guardian (2003).

23. Z. Bauman. Globalizatsiya: posledstviya dlya cheloveka i obzhestva [Globalization: implications for people and society]. Moscow (2004).

24. A. Taggart. We're All Bourgeois Now: The Story of our 200-year-old Obsession with Personal Productivity. https://medium.com/@andrewjtaggart/were-allbourgeois-now-the-story-of-our-200-year-old-obsession-with-personal-productivity-e178bbce766b (Accessed 25 August, 2020).

25. J. Habermas. Buduzhee chelovecheskoy prirody [the Future of human nature.]. Ves' mir, Moscow (2002).

DOI 10.15826/B978-5-7996-3081-2.49

\title{
Creativity in the Film Director's Work: An Example of Works by A. Zvyagintsev
}

\author{
Temlyakova Alina \\ Ural Federal University, Ekaterinburg, Russia \\ ateml@mail.ru
}

\begin{abstract}
This article discusses the main approaches to the definition of creativity, including interdisciplinary ones; in addition, the author highlights a systematic approach to the definition and understanding of creativity at the intersection of psychology, philosophy, and economics. The author reveals the specifics of the analysis of the filmmaker's work through the prism
\end{abstract}


of creativity. The article analyzes the work of the modern Russian film director A. Zvyagintsev in the context of creativity.

Keywords: creativity, film reality, art reality, Russian cinema, A. Zvyagintsev

\section{Introduction}

The author dwells upon the concept of creativity, and analyses how it is applicable to the analysis of a film director's work with the example of Andrey Zvyagintsev's films.

Five films of the contemporary Russian Film director Andrey Zvyagintsev were reviewed and analyzed. According to the title of his lecture "Five views on man and time" those five films symbolizes the views. Both components of this author's view, highlighted in this title ("the man" and "the time") are not constants, they are variables that are subject to constant fluctuations, which the film director sees and depicts in his films.

A constant, a unique unit in the work of this film director, consists of referring to the achievements of world art, culture, masterpieces of painting and music. In such a way, Zvyagintsev reflects today's reality, testing the very foundations of modern life. Everyday stories shown by the film the timeless events, occuring in mythological space and time

The purpose of the article is to analyze the film director's work through the category of creativity and to detect the points of greatest concentration of ideas that give the film significance and artistic value.

\section{Research material}

The research material consists of five full-length feature films: "The Return" (2003); “The Banishment" (2007); "Elena” (2011); "Leviathan” (2014); "Loveless" (2017). We also include A. Zvyagintsev’s interviews materials, books and film scripts. The director's first film “The Return” (2003) received a Golden Lion at the Venice Film Festival, and the national "Nika" and "Golden eagle" awards as the best film of the year. His second film "The Banishment" (2007) represented Russia in the main competition of the 60th Cannes film festival. Also this film won the prize of the Federation of Russian film clubs at the 2007 Moscow film festival. Elena (2011) won the special jury prize for the Special view competition at the Cannes film festival; Leviathan (2014) won the Golden globe award for best foreign language film, as well as the best screenplay award at the 67th Cannes film festival; Loveless (2017) won the jury prize at the 70th Cannes film festival. 


\section{Research methods and methodology}

Analysis of films, written printed sources (books, interview texts), and the film director's video interviews.

\section{Research}

In our time, the word "creativity" is not just widely used, but is used in many different meanings. All available definitions fall into one or more of the following categories:

- individual talent;

- process;

- result;

- public recognition.

Here are the specifics of defining creativity - creativity as a talent inherent in an individual. The essence of this approach is in the idea that "creativity" is an innate individual talent but in this case a tautology may arise: "Creativity is what creative people do."

Creativity of consciousness is based on the individual's ability to create new ideas and images. There are two closely related stages in this process. At the first stage, a person comprehends the available material. The second stage is the emergence of a new idea and the search for ways to apply it in practice. The forms of the creative process are diverse. In our opinion, they are determined, first of all, by the originality of the individual and the area of activity [Daragan, 2011, 197].

Creativity of consciousness is manifested in selectivity, purposefulness of perception and memory, in the creation of ideas, and images that did not previously exist in the individual's or the public consciousness, ass well as in acts of imagination, fantasy, research activities, works of art creation, various forms of ideal anticipation of the future, the promotion of scientific problems, hypotheses and theories [Daragan, 2011, 202].

A number of researchers argue that it is more correct to understand creativity not as an ability, but as a certain mood, intentionality [Stoletov, 2014, 43] but in relation to the creative process itself, creativity acts as a quality of the process, a certain kind of orientation, intentionality, which I divide into intensive and extensive types. Intense creativity dwells upon ontological fundamentals by revelation and the creation of a parallel existence and reality. In this case, the novelty is existential. Extensive creativity reflects the desire to expand its influence on empirical reality by analyzing 
it, identifying the laws of interaction and creating new things: mechanisms, machines, etc. - that is, to change the material world and create material values [Stoletov, 2014, 49].

The need to combine both types of creativity is obvious. Creativity acts according to the principle of complementarity. It can be thought of as a state of primal emptiness that is human openness to the world. In this case, creativity is a personal quality, a special state of the subject that precedes the process that we later call creative. It appears as an opportunity to break away from the existing structure in an attempt to create a new one [Stoletov, 2014, 52].

Creativity as a process. In this approach, the word "creativity" means "creative process". Writer Arthur Koestler describes creativity as "the accidental bringing together of two unrelated ideas." As a definition of creativity, he used the mechanism of generating creative ideas. It can be assumed that a combination of initially unrelated ideas can serve as a source material for ideological creativity, but it cannot be called equal to the generation of "creative ideas". So, despite its importance, the creative process does not reflect the concept of creativity.

But creativity (in contrast to creation) is not a process, but a certain characteristic of the process, the features of its course [Stoletov, 2014, 48]. Creativity as a product, in this case we can talk about "works of art" or "great achievements in different fields". A significant aspect of activity in this case is the presence of a "creative approach" in the process of problemsolving. However, you can look at the creative act in a broader context.

Creativity as something that has been recognized by others. Some people consider this recognition by the wider community as the main feature of the creativity phenomenon. The meaning of the creative process, in addition to its starting point, when it is initiated by the author, is also in the recognition of its result by other people. They also need to demonstrate creative abilities and understanding to perceive and evaluate the work. For example, it is not enough for one artist to have creative abilities, the public must also have them in order to adequately assess the quality of the work.

One of the world's leading experts on creativity, Professor Morris Stein gave the following definition: “...creativity is a process as a result of which something new appears. Something that at a particular time is perceived by a group of significant individuals as useful, reasonable, or satisfying." By "a group of significant individuals", he means those who have sufficient authority or power to establish a scale of values. The emphasis on defining value 
and identifying the cultural context inherent in this approach is an important element in the process of defining creativity. [Green, 2003, 17]

Creativity is not possible if there is no creative environment. The components responsible for the creative process interact with each other and the cumulative effect of their interaction is not reducible to the influence of any one of them. Motivation can compensate for the lack of a creative environment, and intelligence, interacting with motivation, significantly increases the level of creativity [Druzhinin, 2007, 199]. The creative environment means the sphere, structure, and social context that forms the requirements for the creative product.

S. Mednik in his psychological concept considers associations to be the core of creativity. In his opinion, the division of the cognitive act into convergent and divergent components is a wrong representation of the creative process. Creativity is the ability to overcome stereotypes at the final stage of mental synthesis and in the field of associations. The creative process may be considered a reformulation of associative elements into new combinations. The creative solution deviates from the stereotypical one. The criteria for creative solutions is the amount of deviation from the stereotype [Velichko, 2014, 629].

Creativity is a system (multi-level, multidimensional) of mental education that not only includes intellectual potential, but is also associated with motivation, emotions, level of aesthetic development, existential, communicative parameters, competence, etc. [Ilyin, 2009, 159].

Druzhinin V.N. gives the following definitions of terms:

Creative - a creative person who uses non-standard ways of solving problems, capable of original and non-standard actions, discovering new things, creating unique products.

Creativity (from lat. creatio - creation) - the general ability to create, characterizes the individual as a whole, manifests itself in various areas of activity, is considered as a relatively independent factor of giftedness.

Potential creativity is a term used by a number of authors to characterize the innate prerequisites of creativity.

"Specialized" creativity - the ability to create in a particular area of human activity (literary, musical, scientific creativity, etc.), develops on the basis of general creativity under the influence of experience [Druzhinin, 2007, 353-356]. 
In the large psychological dictionary of A. Reberis is given this definition of creativity: "Creativity is a term used...to refer to mental processes that lead to decisions, ideas, thinking, creating artistic forms, theories, or any products that are unique and new."

J. Perry-Smith and K. Shalley define it as follows: "People can be creative in their work by generating new ways of doing their work, coming up with new procedures or innovative ideas, or by using already known approaches in a new environment... We give the following working definition of creativity at the individual level: it is an approach to activity (work) that leads to the generation of new and relevant ideas, processes and solutions." In this definition, the authors again focus on the "productive" component of the creative process.

Many authors in their understanding of the essence and content of the concept of creativity focus on its procedural side. Thus, E. Torrance equates creativity to creative thinking, considering that it is related to the problem-solving process and includes the following components:

- being sensitive to problem situations;

- searching for, highlighting and formulating a problem;

- generating hypotheses about how to solve the problem;

- testing these hypotheses;

- finding and formulating solutions;

- interpretation and promotion of results.

An important role in the creative process is playing person's sensitivity to contradictions. This allows them to identify the problem area within which they can solve the problem [Yagolkovskii, 2007, 16-17].

Contradictions can be identified in the process of dialogue, when the problem area appears in the context of the task discussion. In this regard, sensitivity to contradictions can be not only a personal feature, but also a characteristic of the process of exchanging ideas between several people.

"Processual" definitions of creativity, given by some authors, focus on the activity of a person in the direction of disclosure and realization of his creative potential. Here "creativity" is understood as a personal characteristic, but not as a particular set of personal traits, but as a person's realization of their own individuality. Human individuality is unique, so the realization of individuality is a creative act (bringing into the world a new, previously non-existent). From our point of view, the characteristics of creativity are not objective (in the sense of having a product - material or ideal), but are 
processual, since creativity is considered as a process of identifying one's own individuality. This definition reminds the definition of creativity given by A. V. Libin. He considers the phenomenon of creativity as a special form of self-expression associated "with a constructive tendency in the development of the individual and activity aimed at creation, not destruction." [Yagolkovskii, 2007, 17-18].

Due to the complexity of the concepts of "creativity" and "creation", it is extremely difficult to give their full and correct definitions. The most appropriate understanding of creativity allows us to consider it as a phenomenon that combines both the "effect" and "process" sides. It is important to emphasize that its study as a person's ability to create an original product requires taking into account the subjective and objective novelty of this product. In this understanding, creativity is a complex of phenomenological, individual and socio-cultural aspects. They appear both at the level of its determination, and at the level of demand and evaluation of the results of creativity on the part of the socio-cultural environment [Yagolkovskii, 2007, 18-19].

Focusing on a particular factor that affects the understanding of the concepts of "creation" and "creativity" can lead to the formation of a separate direction in their research.

For a more detailed description of research on creativity and creativity, we will use a classification of approaches: each level determines the field of psychological categories and the positions from which the analysis is carried out. The proposed classification reflects not only the levels of creativity study, but also specific research subjects. In accordance with the provisions, we have identified the following main approaches to the study of creation and creativity.

1. Psychophysiological (biometric) approach, in which the subject of research is the biological and psychophysiological prerequisites of creating processes and creativity.

2. Cognitive-emotional approach aimed at studying the cognitive and emotional aspects of creativity and creation activity.

3. Personal approach, focused on the study of the features and traits of the creative personality.

4. Economic and pragmatic approach, which studies the features of the creative process and its products in specific socio-economic conditions.

5. Systematic approach that involves the study of creativity and creation of a person in unity and relationships with his socio-cultural environment, 
economic reality, as well as the problem area in which his creative activity is carried out [Yagolkovskii, 2007, 21].

It can be noted that many researchers of innovation and creativity, in particular S. Majaro, J. Heap and P. Titas, tend to adhere to the following point of view: creativity is the ideas that arose in the author's imagination, and innovation is an already implemented idea, or an idea applied in practice [Yagolkovskii, 2007, 72].

The effectiveness of narrow-disciplinary approaches to the study of creativity has been very limited, since most of them are focused on the selection and analysis of one component. In this case, the entire complex of relationships contained in it is lost. In a narrow-disciplinary approach, one component of creativity is taken out of the entire context of human creative activity. All this points to the need to use a multidisciplinary approach, which involves taking into account social, cultural, economic and other factors that affect human creativity.

One of the proponents of a systematic approach to the study of creativity is D. Simonton. In his research, he focuses on the study of the interaction of various factors that determine creativity, and on the role of the social and cultural environment of a person in the manifestation and development of creativity.

M. Csikszentmihalyi is also an active proponent of the multidisciplinary approach. In his works, he pays special attention to the study of the interaction between a person, a subject area, and the environment. In his opinion, the basis of the system model of creativity is the idea that the environment of the Creator consists of two main components: cultural and social. In the process of creativity, he interacts with this environment, making changes to it. It is assumed that there is a certain community of people who have similar thinking styles, learn from each other, and/or imitate each other. In addition to coming up with original ideas, a person must find a way to convince their colleagues of their correctness. According to Csikszentmihalyi, the ability to convince the environment of the importance of accepting and implementing original ideas and innovations is an important aspect of realizing creative potential [Yagolkovskii, 2007, 35-36].

Csikszentmihalyi also points out that the level of economic development of society has a significant impact on the manifestation of creativity. How much creative energy is directed to a particular area depends not only on the number of people who actively show themselves in this area, and their 
level of creativity, but also on how much their creative achievements are in demand by society.

The System approach allows us to identify and study "external" factors that affect a person's creativity, providing an opportunity to analyze the processes of interaction between a creative person and his environment. This requires the development and use of methods for assessing this impact. One of the most popular methods is the psychometric method for evaluating various parameters of creativity [Yagolkovskii, 2007, 36].

The analysis of the main approaches to the study of human creativity and creativity shows that most of them study these psychological categories only at one level. However, there is now an urgent need for a multi-level analysis of them. Such an analysis can be carried out within the framework of a systematic approach that allows us to study not only personal, but also social, cultural, economic and other determinants of human creative activity. The emergence of this approach is due to an increase in the level of analysis of these psychological categories.

There are quite a lot of other areas in study of creation and creativity in addition to the describing approach [Yagolkovskii, 2007, 39-40].

\section{Results interpretation}

The film director's creativity can be studied using a systematic approach to understanding creativity. This is both the creativity of a single person (artist), and the context in which the act of creating and releasing a film takes place, as well as the surroundings (critics, journalists, viewers), which are able to evaluate the work and recognize the category of creativity. The creativity of the director as an individual consists in the ability to construct a unique film reality. Now we will reveal the characteristic features of the film reality of films directed by Zvyagintsev. First of all, it is worth noting that the film reality of the director's films is extremely culture-centric.

The language of the films of. Zvyagintsev is woven from different modal quotes: cinematic, pictorial-graphic, sculpture-statuary, rhythm-melodic, musical, television. At the same time, the master so confidently subordinates the fragments and allusions to the logic of his artistic narration, that a unique author's work is born out of the intermedial and multimodal intertextual fabric. Picturesque lines of frescoes of the Ferapontov Monastery, landscapes of I. Levitan and N. Kuindzhi, pictures of P. Bruegel the Elder and I. Bosch, literary motifs of F Dostoevsky and A. Chekhov, M. Gorky and A. Camus, 
movie motifs of A. Tarkovsky and I. Bergman are used in Zvygintsev's films [Gudova, 2019, 1043].

Some scenes of his films refer to the canvases of the greatest works of fine art. For example, in one of the scenes in the film "Loveless" (2017), which shows children playing in the snow and figures of passers-by near the heroes ' house, we see an allusion to the painting by Pieter Bruegel the Elder "The Hunters in the Snow" (Jagers in de Sneeuw; 1565). It shows the irreversibility and serenity of the course of life against the background of the tragedy of the heroes ' lovelessness. The film also shows the color scheme and mood of paintings by Andrew Wyeth(1917-2009), Edward Hopper (1882-1967), Rockwell Kent (1882-1971), Thomas De Keyser (1596-1679) (“The Company of Cpt. Allaert Cloeck and Lt. Lucas Jacob”, 1632, a scene in an elevator with the main character, the boy's father), Rene Magritte (1898-1967) (“The lovers" (1928), blindfolded as a representation of total closeness or deliberate closing from reality), by Pablo Picasso (1881-1973). In the movie "The Banishment" (2007), children collect a puzzle in the form of Leonardo da Vinci's painting "the Annunciation" (1472-1475). It is known that the references to "The Banishment" (2007) were the canvases of the American artist Andrew Wyeth (1917-2009), which set the color and aesthetic framework of the film, and also give the film scenes a mood of irresistible loneliness for each of the characters. The scene with the sleeping father in the film "The Return" (2003) - repeats the composition of the painting "Dead Christ" (1490) by the Italian artist of the early Renaissance Andrea Mantegna. This approach, which implies quoting and allusions of the director to the works of world art culture, introduces its own aesthetic framework, in addition to the frame of the film frame itself.

The space-time continuum of the films is defined by events of the present time and modernity. These are houses, blocks of new buildings, disadvantaged areas ("Elena", 2011), clothing, furniture, acting as "markers" of rich and poor life, middle class life ("Loveless", 2017). Signs are literally read by the gaze of the beholder. However, the special emphasis of the prolonged disturbing chord (Philip Glass, Arvopärt) is left by the plots displayed by the director, which can be conditionally called "Chronicles of the inevitable", arising from seemingly everyday situations: the arrival of the father ("The Return", 2003); pregnancy of the spouse (“The Banishment", 2007); making a will ("Elena", 2011); divorce of the spouses ("Loveless", 2017). 


\section{Conclusions}

The director's creativity is manifested in the ability to work with various significant sections of reality, to organize the movie reality, saturating it with relevant meanings through reference to the achievements of world art culture (quotes, references, visual, auditory and color images).

Also, the most important feature of. Zvyagintsev's film reality is intertextuality, which is one of the most important strategies for constructing the text of a work of art in modern postmodern art. Moreover, we can also talk about hyperintertextuality as the construction of more intense and explicit connections between texts and artistic statements. As a result, individual texts are instantly linked to many other discourses. The hyperintertextuality inherent in Zvyagintsev's work makes it possible to raise the viewer's inner gaze from a private plot presented in films to reflections on the eternal, on the meaning of human life and the future of humanity.

As a conclusion, we can highlight the features of the film reality of Zvyagintsev's films. We have reviewed and analyzed the films "The Return", "The Banishment", "Elena”, "Leviathan", "Loveless" and we can say that the general characteristics of the space-time reality are, on the one hand, a kind of mythological plot that refers to some eternal history from the field of myth.And on the other hand, stringing this plot on the realities of modern Russia, with an emphasis on the director's own disturbing worldview, when ordinary actions gradually lead to horrific tragic results, each of his movies. The time axis is characterized by Zvyagintsev's consistent development of events, this is the time of the origin of the conflict and its resolution. Space acts as a space of "conflict resolution", it is a modern city, district and its surroundings in each of the films. Moreover it should be emphasized how the director uses the film language to create a timeless atmosphere - this is a remote island in the movie "The Return", a house on a hill in the movie "The Banishment", or a house on the bay in the movie "Leviathan", when we see a giant whale swimming in the waters of the sea or the skeleton of a huge cetacean on the shore.

It means that Zvyagintsev shows us, as it seems at first glance, the usual coordinated system, but by introducing his own author's marks, markers, he gives it a cultural-centered meaning; the director enters into a dialogue with the audience, relying on the system of eternal artistic and cultural values of humanity. 
The creativity of the director can be marked as a system category (through a system approach), covering both the act of thinking of the film director himself, including his socio-cultural environment, as well as the process of creating the film's environment (cinematographic methods and techniques) - creativity as a product or result. In this case, it is a film that touches a certain problem area, released and received wide international recognition.

\section{Acknowledgments}

The research was carried out with the financial support of the RFBR in the framework of research project No. 18-311-00235.

\section{References:}

1. N.D. Daragan. O kreativnosti soznaniya [About the creativity of consciousness]. Vestnik TGPI [Bulletin of Taganrog state pedagogical University] № 2 (2011.) Pp. 196-202.

2. A.I. Stoletov. Sushchnost' kreativnosti i yeye tipy [The essence of creativity and its types] Mezhdunarodnyy zhurnal issledovaniy kul'tury. [International Journal of Cultural Research]. № 4 (17) (2014). Pp. 43-52.

3. E. Grin. Kreativnost' v pablik rileyshnz/Per. s angl. pod red. A. N. Andreyevoyp [Creativity in public relations/Translation from English under the editorship of A. N. Andreeva]. Neva Publishing House, St. Petersburg (2003).

4. V.N. Druzhinin. Psikhologiya obshchikh sposobnostey. 3-ye izd [Psychology of general abilities. 3rd edition.]. Piter Publishing House, St. Petersburg (2007).

5. U.V. Velichko. O sootnoshenii ponyatiy "kreativnost", "tvorcheskiye sposobnosti", "tvorcheskoye voobrazheniye", "tvorcheskoye myshleniye" v issledovaniyakh otechestvennykh i zarubezhnykh psikhologov [About the correlation of the concepts "creativity", "creative abilities", "creative imagination", "creative thinking" in the research of domestic and foreign psychologists]. Izvestiya Samarskogo nauchnogo tsentra Rossiyskoy akademii nauk [Bulletin of the Samara scientific center of the Russian Academy of Sciences]. vol. 16, № 2 (3) (2014). Pp. 629-631.

6. Y.P. Il'in. Psikhologiya tvorchestva, kreativnosti, odarennosti [Ilyin E. P. Psychology of creativity and giftedness]. Piter Publishing House, St. Petersburg (2009).

7. S.R. Yagolkovskiy. Psikhologiya kreativnosti i innovatsiy: ucheb. posobiye [Psychology of creativity and innovation: textbook]. Higher school of Economics, Moscow (2007).

8. M. Gudova. Contemporary existential philosophy and an intermedial language of a cinema (on the example of a Zvyagintsev's films) // International Congress 
of Aesthetics $(21 ; 2019$; Belgrade) Possible worlds of contemporary aesthetics: aesthetics between history, geography and media [Elektronskiizvor] : proceedings / 21st International Congress of Aesthetics ICA 2019, Belgrade, 2019. - Belgrade : University of Belgrade, Faculty of Architecture, 2019 (Belgrade : GrafikCentar). (CD-ROM) ; $12 \mathrm{~cm}$ - pp. 1042-1046.

DOI 10.15826/B978-5-7996-3081-2.50

\section{Art \& Science Potential in the Development of Russian Scientific Communication in the Museum Exhibition Policy Context}

\section{Yarmosh Anastasia Sergeevna}

St. Petersburg State University, St. Petersburg, Russia a.yarmosh@spbu.ru

Abstract: Art projects are usually expected to have the form of dual communication. Now we can see growing interest in the modern practice of technological art in Russia. The key aspect of the human-oriented models development is seen in the results of scientific and technological development actualization through the complex objects of art \& science. This is proved by the example of the interdisciplinary project "ChaosMeasure: science as a way of communication".

Keywords: exhibition project, media environment, modern museum, scientific communication, technological art

\section{Introduction}

Today, we can state a century of technological art development in Russia in the context of a changing historical picture, political discourse, and world concepts. Some examples of technological (scientific) art in Russia of the twentieth century were interpreted in the study of the practices of the avant-garde, underground and nonconformism, contemporary art of the turn of the XX-XXI centuries. At the same time, there was so little attempts to consider technological (scientific) art as an original phenom- 